\title{
Warm up practices of golfers: are they adequate?
}

\author{
A J Fradkin, C F Finch, C A Sherman
}

\begin{abstract}
Background-Although it is widely recommended that golfers warm up before play or practice to enhance their physical performance and reduce their injury risk, it is not known to what extent they actually undertake such warm up procedures.

Objective-To collect information about the proportion of golfers who actively warm up and to determine the types of warm up behaviours.

Methods-This study was conducted over three weeks at three different golfing venues: a private golf course, a public golf course, and a golf driving range. Golfers' warm up behaviours, defined as any form of preparative exercise, were recorded by direct observation by two independent observers.

Results-The sample consisted of 1040 amateur golfers (852 men and 188 women) aged at least 18 years. Only 54.3\% (95\% confidence interval 49.8 to 58.8 ) performed some form of warm up activity. Air swings on the tee were the most commonly observed warm up activity, with $88.7 \%$ (95\% confidence interval 85.9 to 91.5) of golfers who warmed up performing these.

Conclusions-Only a small proportion of amateur golfers perform appropriate warm up exercises. To improve on this, golfers should be educated about the possible benefits of warming up and be shown how to perform an appropriate warm up routine.

(Br F Sports Med 2001;35:125-127)
\end{abstract}

Keywords: behaviour; observational study; golf; warm up; injury prevention

Golf is a popular sport reflecting the fact that it has no age or sex limits. As with all sporting activities, it is widely recommended that golfers undertake a warm up routine before starting their golf. ${ }^{12}$ Warm up is defined as a period of preparatory exercise undertaken to enhance subsequent competition or training performance. $^{3}$

It is generally believed that preparing the body before play benefits performance and decreases the risk of injury. ${ }^{124}$ However, the recommendations for appropriate warm up practices in the golfing literature have been inconsistent. ${ }^{2}$ An appropriate warm up for golfers should include a period of aerobic exercise to increase body temperature, followed by stretching of the "golf muscles" (hands, wrists, forearms, shoulders, lower back, chest, trunk, hamstrings, and groin). ${ }^{15-13} \mathrm{~A}$ series of golf swings with a progressive increase in range of motion and vigor should then be performed. ${ }^{145913}$

To date, no golf specific studies have investigated the benefits of warming up. Also, there have been no studies that describe the types of warm up activities that are undertaken, the extent to which these are undertaken, or which types of golfer actually do warm up. ${ }^{2}$ Before strategies to encourage and educate golfers to warm up can be implemented, it is important to understand current warm up behaviours. ${ }^{2}$ The purpose of this study was therefore to collect information about the proportion of golfers that warm up and to determine the types of warm up they undertake.

\section{Method}

The warm up behaviours of amateur golfers aged 18 years and over were observed at three different golfing venues: a private golf course, a public golf course, and a golf driving range. Observational data was collected over three weeks in June 1999 with each venue randomly visited 10 times. During each three hour session, two independent observers recorded the warm up behaviours of golfers.

\section{SAMPLING PROCEDURE}

Golfers were randomly selected for observation at the private and public courses by the order in which they arrived at the tee off area. Criteria for subject selection were dependent on both observers watching the randomly selected golfers as soon as their group made their way to the tee off area. Groups were excluded from this study if they were not observed from the time they arrived in the tee off area, up until and including the time they hit off.

Golfers at the driving range were randomly selected on the basis that they were observed by both observers from the time they purchased their bucket of golf balls, up until and including the time they hit their first golf ball.

OBSERVATIONAL PROCEDURES

On their arrival at the public and private courses, the two observers selected separate areas from which unobstructed observation of the golfers' warm up activities could be undertaken. These areas had a clear view of both the tee off area and practice nets. At the driving range, the two areas were selected so that there was a clear view of where the golfers purchased practice balls and the stalls from where they hit their balls.

A standardised observational procedure (including a data record sheet) was developed and used. The number of air swings both on and off the tee were counted, as well as any form of aerobic exercise (such as star jumps). A description of the types of aerobic exercise, the 
Table 1 Number of golfers observed undertaking each type of warm up activity ( $n=1040)$

\begin{tabular}{|c|c|c|c|c|c|}
\hline \multirow[b]{2}{*}{ Warm up activity } & \multirow{2}{*}{$\begin{array}{l}\text { Number of golfers who } \\
\text { performed a warm up } \\
\text { activity }(n=1040)\end{array}$} & \multirow{2}{*}{$\begin{array}{l}\% \text { of observed golfers who } \\
\text { performed each warm up activity } \\
(n=1040)(95 \% \mathrm{CI})\end{array}$} & \multirow{2}{*}{$\begin{array}{l}\% \text { of golfers who warmed up } \\
\text { undertaking each activity } \\
(n=565)(95 \% \text { CI) }\end{array}$} & \multicolumn{2}{|c|}{$\begin{array}{l}\text { Average number of repetitions by those } \\
\text { who performed each activity }(n=565)\end{array}$} \\
\hline & & & & Median & Range \\
\hline Air swing on tee & 501 & 48.2 (43.8 to 52.6$)$ & 88.7 (85.9 to 91.5$)$ & 2.0 & $0-12$ \\
\hline Air swing before tee & 199 & 19.1 (13.6 to 24.6$)$ & $35.2(28.8$ to 41.6$)$ & 1.0 & $0-8$ \\
\hline Dynamic stretch & 97 & $9.3(3.5$ to 15.1$)$ & $17.2(9.7$ to 24.7$)$ & 1.0 & $0-3$ \\
\hline Static stretch & 31 & $2.9(0.0$ to 8.8$)$ & $5.4(0.0$ to 12.0$)$ & 1.0 & $0-2$ \\
\hline Aerobic activity & 0 & $0.0(0.0$ to 0.0$)$ & $0.0(0.0$ to 0.0$)$ & 0.0 & $0-0$ \\
\hline
\end{tabular}

number of repetitions, and the muscle group used was recorded. In addition, both static stretches-that is, stretches held in a set position-and dynamic stretches-that is, stretches moving through a wide range of motion-were recorded separately, with the number of stretches and the broad muscle groups used also recorded.

As two independent observations were made for each golfer, the interobserver agreement was calculated in order to obtain a measure of the reliability of the observations. This was found to be $99.9 \%$, indicating a high level of reliability.

Approval was obtained from the Deakin University ethics committee, and written consent was obtained from the managers of each venue before the start of the study.

\section{Results}

A total of 1040 golfers were observed, with most being men $(81.9 \%$ of the total, $95 \%$ confidence interval 79.4 to 84.4 ).

Table 1 shows that $54.3 \%(n=565)$ of the golfers performed some form of warm up. Of the golfers who were observed to warm up, most undertook air swings on the tee, followed by air swings before the tee. No golfer undertook aerobic activity and very few performed static stretches. Only three muscle groups were observed to be dynamically stretched, with the shoulder being stretched most often $(73.2 \%$ of all golfers who stretched dynamically). The two other muscle groups stretched were the trunk $(21.3 \%)$ and lower back $(5.5 \%)$. Only three muscle groups were observed to be statically stretched: the shoulder (73.7\% of all golfers who stretched statically), the wrist $(21.1 \%)$, and the hamstrings $(5.2 \%)$.

Most golfers who warmed up performed only one type of activity $(77.0 \%)$. Only $17.8 \%$ of golfers performed two different warm up activities, and even fewer $(0.4 \%)$ performed all four warm up activities.

Few golfers were observed performing multiple repetitions of each warm up activity (table $1)$. On average, golfers performed more than one air swing off the tee (median 2 repetitions). In all other warm up activities the median number of repetitions was one.

\section{Discussion}

This study presents information about the warm up activities of a sample of observed amateur golfers. Almost half of the golfers in our sample did not perform any warm up before play or practice. Those who undertook some form of warm up were more likely to perform air swings than stretches or aerobic exercise. This limited warm up activity is unlikely to be adequate to achieve either performance or injury prevention benefits. ${ }^{4}$ Air swings are an important activity to perform, but they do not constitute an appropriate warm up routine in themselves. ${ }^{14}$ Although the stretches performed targeted one of the main golfing muscle groups (the shoulder), the other major muscle groups were generally neglected. Fewer than $3 \%$ of golfers in our sample can be considered to have warmed up adequately. These golfers performed at least one set of stretches and air swings - that is, they performed at least three different warm up activities.

As this is an observational study, there are some limitations in the data presented. It is possible that the golfers who did not warm up on the day of the observation usually do so, but not on that day. Furthermore, it is possible that some golfers performed a warm up out of view of the observers-for example, in the car park. Further studies are needed to determine the extent to which golfers also warm up before reaching the tee off area.

If golfers do not perform an adequate warm up routine as this study suggests, they may place themselves at risk of injury. ${ }^{2}$ Although there is a lack of scientific evidence to link warming up to reduced injury risk, many authors believe a properly conducted warm up procedure reduces the chance of injury during golf. ${ }^{2}$ However, as the benefits of golf warm up procedures have not been formally studied, the current recommendations for such activities are inconsistent. ${ }^{2}$

In conclusion, this study provides information about the extent and type of warm up practices undertaken by golfers. Future research should be directed towards developing an appropriate golfing warm up routine and formally evaluating its injury prevention and performance benefits. In addition, information on golfers' knowledge about and attitudes towards warming up need to be determined. With this information, strategies to educate golfers about the benefits of warming up and how to perform an adequate warm up procedure will be able to be developed and promoted.

This study was undertaken by A F as part of her Bachelor of Applied Science Honours degree at Deakin University, under the supervision of C A S and C F F. C F F was supported by a Public Health Research and Development Committee (of the Nublic Health Health and Medical Research Council) Research Fellowship. Dr Andrew Garnham is also thanked for his valuable comments on this project.

1 Mallon WJ, Hawkins RJ. Injuries in golf. In: Renstrom PAFH, ed. Clinical practice of sports injury prevention and care: volume $V$ of the encyclopedia of sports medicine. Oxford: care: volume $V$ of the encyclopedia of sports medici

2 Sherman CA, Finch, C.F. Preventing injuries to competitive and recreational adult golfers: what is the evidence? $\mathcal{F} S \mathrm{Sc}$ Med Sport 2000;3:65-78. 
3 Hedrick A. Physiological responses to warm-up. National Strength and Conditioning Association fournal 1992;14:25-7. Stover CN, Mallon WJ. Golf injuries: treating the play to treat the player. Fournal of Musculoskeletal Medicine 1992,9.55-72. Adlington GA. Proper swing techniques and biomechanic of golf. Clin Sports Med 1996;15:9-26.

6 Brendecke P. Golf injuries. Sports Medicine Digest 1990;12 $1-2$.

7 Buchan JF. Golf injuries: treatment and prevention. In Payne SDW, ed. Medicine, sport and the law. Oxford: Blackwell Scientific Publications, 1990:354-9.

8 Galanty HL, Puffer, J.C. Golf. In: Mellion MB, ed. Sports medicine secrets. Philadelphia: Hanley \& Belfus Inc, 1994:390-5
9 Hosea TM. The golf swing: diagnosis, pathophysiology, and treatment of back problems. In: McCarroll JR, Stover, C.N, eds. Golf medicine. Philadelphia: FA Davis Company, 1993.

Jobe FW, Schwab DM. Golf for the mature athlete. Clin Sports Med 1991;10:269-82.

11 McCarroll JR. Golf. In: Fu FH, Stone DA, eds. Sports injuries: mechanisms, prevention, treatment. Baltimore: Williams \& Wilkins, 1994:375-81.

12 Pink MM, Jobe FW, Yocum LA, et al. Preventative exercises in golf. Clin Sports Med 1996;15:147-62.

13 Theriault G, Lachance, P. Golf injuries: an overview. Sports Med 1998;26:43-57.

14 Dalgleish M. Warm up. Strength and Conditioning Coach 993;1:8-9.

Take home message

Few amateur golfers perform appropriate warm up routines before play or practice. Education of amateur golfers about the possible benefits of warming up and how to perform an appropriate warm up procedure needs to be implemented.

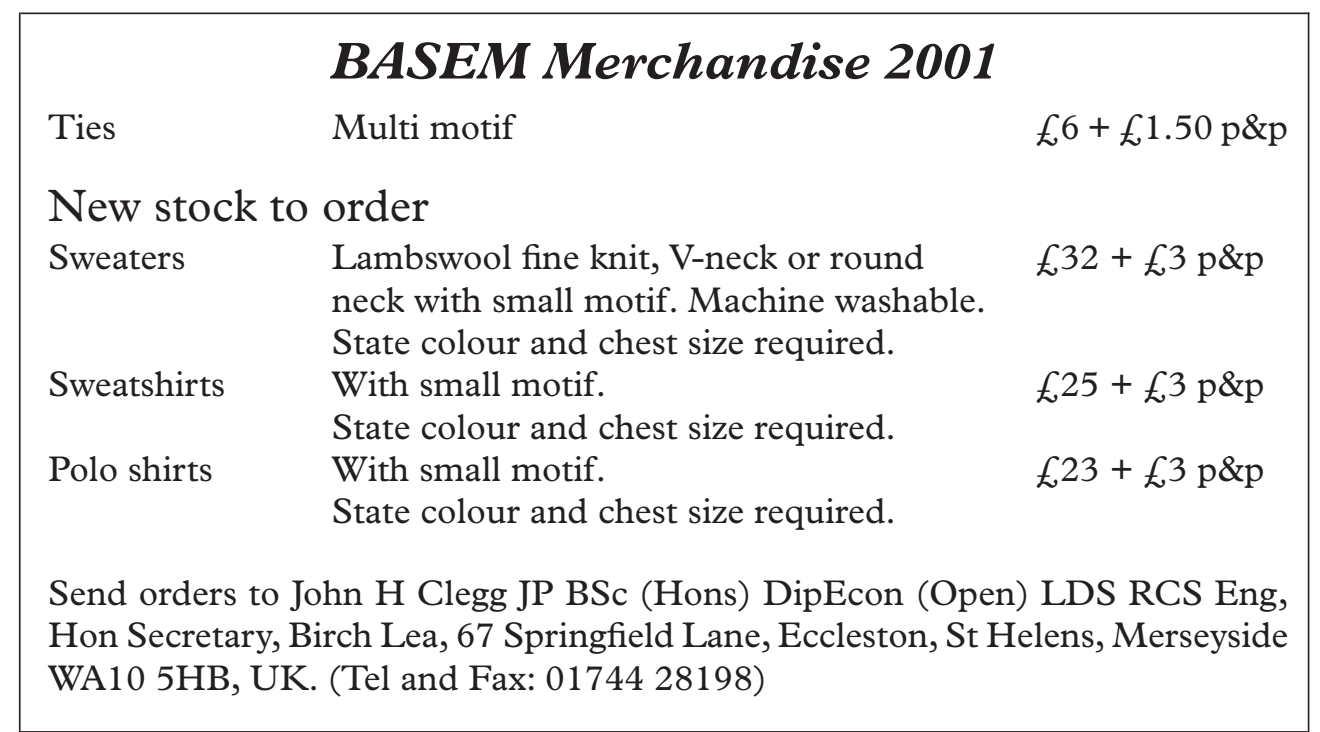

